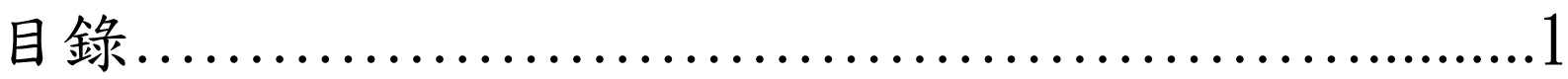

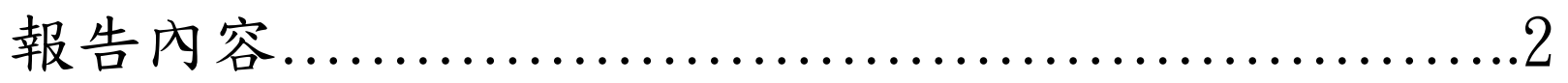

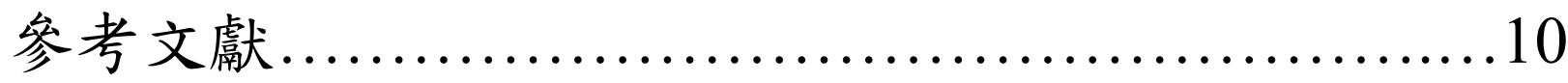

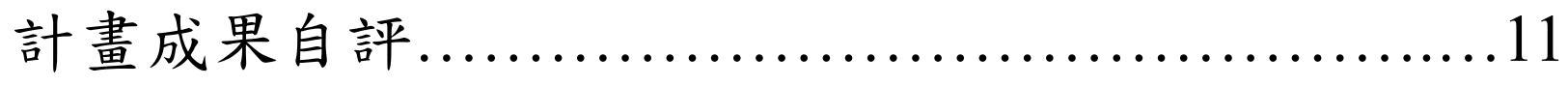

可供推廣之研發成果資料表 ..........................12 


\title{
Maximum-Likelihood Decoding for Nonorthogonal and Orthogonal Linear Space-Time Block Codes
}

\author{
Hong-Yu Liu and Rainfield Y. Yen
}

\begin{abstract}
It is a general consensus that an orthogonal space-time block code can achieve full diversity, and due to its orthogonal nature, the multiple-input-multiple-output (MIMO) maximum-likelihood (ML) decoding metrics can be decoupled into single-input-single-output (SISO) ML metrics based on linear processing at the receiver, thus greatly reducing the decoding complexity. In fact, nonorthogonal codes also currently exist that can achieve better symbol-error-rate performance without rate reduction and complexity increase for correlated fading channels. In this paper, we show by detailed derivations that nonorthogonal linear space-time block codes can also be decoded by ML decoupling through receiver linear processing. Our derived expressions for the decoupled ML metrics automatically contain the design information for the receiver linear processors.
\end{abstract}

Index Terms-Antenna diversity, fading channels, linear space-time block codes (LSTBCs), orthogonal space-time block codes (OSTBCs).

\section{INTRODUCTION}

$\mathbf{I}$ T IS a general impression that due to the orthogonal structure of the orthogonal space-time block code (OSTBC), simple maximum-likelihood (ML) decoding based on linear processing at the receiver can be achieved through decoupling of transmitted signals [1]-[7]. Moreover, the OSTBC can be designed to achieve maximum diversity order [5]. Therefore, it has gained vast popularity. Several codes with a complex orthogonal design (COD) [5], [8]-[13] and a generalized COD (GCOD) [5], [14] have been unveiled.

Li et al. [15] then presented a general derivation to decouple ML decoding for COD multiple-input-multiple-output (MIMO) channels into single-input-single-output (SISO) ML decoding forms. An equivalent proof with more brief derivation is given in [16]. Later, $\mathrm{Xu}$ and Kwak [17] derived the decoupling of the MIMO ML metric into SISO ML metrics for GCOD channels.

However, a space-time block code (STBC) can also be nonorthogonal. As defined in [16], a major category of the space-time code is the linear STBC (LSTBC) that encompasses both orthogonal and nonorthogonal codes. An LSTBC becomes a COD if and only if the code matrices satisfy the amicable orthogonal design (AOD) [16]. Then, under slightly different conditions, an LSTBC may become a GCOD code. Recently,

Manuscript received September 30, 2006; revised June 18, 2007 and July 28, 2007. The review of this paper was coordinated by Dr. K. Molnar.

H.-Y. Liu is with the Department of Computer and Communication Engineering, Dahan Institute of Technology, Hualien 97145, Taiwan, R.O.C. (e-mail: hongyu.liu@msa.hinet.net).

R. Y. Yen is with the Department of Electrical Engineering, Tamkang University, Taipei 25137, Taiwan, R.O.C. (e-mail: rainfieldy@yahoo.com).

Digital Object Identifier 10.1109/TVT.2007.907287 some researchers have developed a nonorthogonal LSTBC by precoding an OSTBC [18]-[20]. It is shown in [19] that when fading channels are correlated, nonorthogonal codes resulting from optimum precoding of the OSTBC can achieve better symbol-error-rate (SER) performance than the OSTBC. The SER is the ultimate system performance measure and is more important than diversity order. In this paper, we introduce a more general class of LSTBC with code matrix satisfying conditions broader than those of the AOD. Such an LSTBC class may generally encompass orthogonal (including GCOD and COD) and nonorthogonal codes. In fact, the nonorthogonal codes of [18]-[20] fall into this class of LSTBC. We then prove, in a more general way than those given in [15] and [17], which are only for orthogonal codes, that ML decoupling through receiver linear processing is also feasible for this class of LSTBC, whether orthogonal or nonorthogonal. Thus, simple ML decoupling is not a prerogative of only the orthogonal codes. A by-product of our proof derivation is the revelation of the design structures of the receiver linear processors. Moreover, some of the codes discussed here may possess the following properties: 1) that equivalent virtual channel gains for the real and imaginary parts of signal symbols are unequal and 2) that the equivalent additive complex Gaussian noise may be noncircularly symmetric. In short, our contribution is to introduce and formulate a general class of LSTBC that encompasses orthogonal and nonorthogonal designs and prove that nonorthogonal codes can also be decoded through the decoupling of ML metrics. Furthermore, the simple derived forms of the decoupled ML metrics automatically contain design information for the receiver linear processors.

A word is in order here. We have not made available how to construct the said general class of LSTBC. Whether such LSTBCs can be constructed remains an open and challenging subject and, hence, needs to be further investigated. Fortunately, as stated earlier, some LSTBCs that indeed fall into this class have recently appeared in the literature [18]-[20], and a nonorthogonal code constructed following the technique given in [19] is delineated in the numerical example section for demonstration. Although many nonorthogonal codes have yet to be discovered (just like many orthogonal codes have yet to be discovered), it does not mean that they do not exist. Our theory merely opens a door for a further research challenge.

Section II presents the general class of LSTBC with code matrix satisfying the broad conditions. Section III proves the ML decoding capability for this class of LSTBC, whether orthogonal or nonorthogonal. Then, Section IV explores ML decoding for various special cases by relaxing the broad conditions. Section $\mathrm{V}$ gives an example of the existing nonorthogonal 
LSTBC that falls into the general class. Then, the detailed receiver design is presented. Finally, Section VI draws conclusions.

\section{LSTBC With Code Matrix Satisfying BROAD CONDITIONS}

We consider a wireless communication system with $P$ transmit antennas and $Q$ receive antennas employing LSTBC transmission. Let the equivalent baseband path gain from the $p$ th transmit antenna to the $q$ th receive antenna be $h_{p, q}, p=$ $1,2, \ldots, P, q=1,2, \ldots, Q$.

The LSTBC transmission can be described by a $P \times N$ code matrix as [16]

$$
\mathbf{G}=\left[\begin{array}{cccc}
g_{11} & g_{12} & \cdots & g_{1 N} \\
g_{21} & g_{22} & \cdots & g_{2 N} \\
\vdots & \vdots & \cdots & \vdots \\
g_{P 1} & g_{P 2} & \cdots & g_{P N}
\end{array}\right]
$$

Here, $g_{p n}$ is the code word transmitted from the $p$ th transmit antenna at the $n$th time slot, $n=1,2, \ldots, N$, and $N$ time slots constitute a block. Each code word $g_{p n}$ is a linear combination of information symbols $\left\{x_{k}\right\}$ and their conjugates $\left\{x_{k}^{*}\right\}, k=$ $1,2, \ldots, K, K \leq N$. In other words, a set of $K$ information symbols over a block of $N$ time slots are chosen for transmission through $P$ transmit antennas. Thus, the code rate is $K / N$. Different blocks may choose different sets of $K$ symbols. The code matrix $\mathbf{G}$ can also be alternatively expressed by another two $P \times N$ code matrices $\mathbf{A}_{k}$ and $\mathbf{B}_{k}$ as [16]

$$
\mathbf{G}=\sum_{k=1}^{K}\left(x_{k c} \mathbf{A}_{k}+j x_{k s} \mathbf{B}_{k}\right)
$$

where $x_{k c}=\operatorname{Re}\left\{x_{k}\right\}$ and $x_{k s}=\operatorname{Im}\left\{x_{k}\right\}$, with $\operatorname{Re}\{\cdot\}$ denoting the real part of $\{\cdot\}$ and $\operatorname{Im}\{\cdot\}$ denoting the imaginary part of $\{\cdot\}$.

The received signal vector $\mathbf{r}_{q}=\left[r_{1, q}, r_{2, q}, \ldots, r_{N, q}\right]^{T}, T$ denoting transposition, at the $q$ th receive antenna over the block of $N$ time slots is given by

$$
\mathbf{r}_{q}=\mathbf{y}_{q}+\mathbf{n}_{q}=\mathbf{G}^{T} \mathbf{h}_{q}+\mathbf{n}_{q}
$$

where $\mathbf{y}_{q}=\left[y_{1, q}, y_{2, q}, \ldots, y_{N, q}\right]^{T}$ is the noise-free received signal vector, $\mathbf{n}_{q}=\left[n_{1, q}, n_{2, q}, \ldots, n_{N, q}\right]^{T}$ is the zero-mean additive white Gaussian noise vector with the covariance matrix $\sigma_{n}^{2} \mathbf{I}_{N}$, with $\mathbf{I}_{N}$ being the $N \times N$ identity matrix, and $\mathbf{h}_{q}=$ $\left[h_{1, q}, h_{2, q}, \ldots, h_{P, q}\right]^{T}$ is the channel gain vector for the $q$ th receive antenna. In (3), we assume that $\mathbf{h}_{q}$ remains constant over one block of $N$ time slots (quasi-static fading).

We now define three $P \times P$ Hermitian matrices $\mathbf{W}_{k, 1}$, $\mathbf{W}_{k, 2}$, and $\mathbf{W}_{k, 3}$ as

$$
\begin{aligned}
\mathbf{W}_{k, 1} & =\mathbf{A}_{k} \mathbf{A}_{k}^{H} \\
\mathbf{W}_{k, 2} & =\mathbf{B}_{k} \mathbf{B}_{k}^{H} \\
\mathbf{W}_{k, 3} & =j\left(\mathbf{B}_{k} \mathbf{A}_{k}^{H}-\mathbf{A}_{k} \mathbf{B}_{k}^{H}\right)
\end{aligned}
$$

where $H$ denotes Hermition transposition. Suppose we impose the following conditions: For $k=1,2, \ldots, K, i=1,2, \ldots, K$, and $i \neq k$

$$
\begin{aligned}
\mathbf{A}_{k} \mathbf{A}_{i}^{H} & =-\mathbf{A}_{i} \mathbf{A}_{k}^{H} \\
\mathbf{B}_{k} \mathbf{B}_{i}^{H} & =-\mathbf{B}_{i} \mathbf{B}_{k}^{H} \\
\mathbf{B}_{i} \mathbf{A}_{k}^{H} & =\mathbf{A}_{k} \mathbf{B}_{i}^{H}
\end{aligned}
$$

then, we can readily show that

$$
\begin{aligned}
\mathbf{G G}^{H}= & \sum_{k=1}^{K} \sum_{i=1}^{K}\left(x_{k c} \mathbf{A}_{k}+j x_{i s} \mathbf{B}_{k}\right)\left(x_{i c} \mathbf{A}_{i}^{H}-j x_{i s} \mathbf{B}_{i}^{H}\right) \\
= & \sum_{k=1}^{K}\left(x_{k c}^{2} \mathbf{A}_{k} \mathbf{A}_{k}^{H}+x_{k s}^{2} \mathbf{B}_{k} \mathbf{B}_{k}^{H}\right) \\
& +x_{k c} x_{k s} \sum_{k=1}^{K} j\left(\mathbf{B}_{k} \mathbf{A}_{k}^{H}-\mathbf{A}_{k} \mathbf{B}_{k}^{H}\right) \\
= & \sum_{k=1}^{K}\left(x_{k c}^{2} \mathbf{W}_{k, 1}+x_{k s}^{2} \mathbf{W}_{k, 2}+x_{k c} x_{k s} \mathbf{W}_{k, 3}\right) .
\end{aligned}
$$

When the rows of the code matrix $\mathbf{G}$ are orthogonal to each other (resulting in $\mathbf{G G}^{H}$ being diagonal), the codes transmitted from different antennas are orthogonal and are, hence, said to be orthogonal codes. Note that $\left\{\mathbf{A}_{k}, \mathbf{B}_{k}\right\}$ satisfying conditions (7)-(9) do not necessarily yield orthogonal codes and form a broader class than the AOD defined in [16]. The AOD narrows the aforementioned conditions to allow $\mathbf{W}_{k, 1}=\mathbf{W}_{k, 2}=\mathbf{I}_{P}$ and $\mathbf{W}_{k, 3}=\mathbf{0}$, where $\mathbf{I}_{P}$ is a $P \times P$ identity matrix, and hence makes $\mathbf{G G}^{H}$ diagonal. Thus, (10) becomes $\mathbf{G G}^{H}=$ $\sum_{k=1}^{K}\left|x_{k}\right|^{2} \mathbf{I}_{p}$, and the AOD code is just the COD code [5]. On the other hand, if we allow $\mathbf{W}_{k, 3}=\mathbf{0}$ and $\mathbf{W}_{k, 1}=\mathbf{W}_{k, 2}=$ $\boldsymbol{\Lambda}_{k}$, where $\boldsymbol{\Lambda}_{k}$ is a diagonal matrix with positive diagonal entries, the GCOD results [5], [14]. Note that since $\left\{\mathbf{A}_{k}, \mathbf{B}_{k}\right\}$ must be subject to the constraints of (7)-(9), this class of LSTBC is, by no means, the utmost general.

\section{ML Decoding For The LSTBC With BRoAD Conditioned Code Matrices}

We now explore the ML decoding of the LSTBC with code matrices satisfying the broad conditions given in Section II.

The ML decision metric is given by

$$
D_{\mathrm{ML}}=\sum_{q=1}^{Q}\left(\mathbf{r}_{q}-\mathbf{y}_{q}\right)^{H}\left(\mathbf{r}_{q}-\mathbf{y}_{q}\right) .
$$

The decision is reached by minimizing the metric $D_{\mathrm{ML}}$ over all possible information sequences $\left\{x_{1}, x_{2}, \ldots, x_{K}\right\}$. Assuming each $x_{k}$ is selected from an $M$-ary signal constellation, we must compute $M^{K}$ metrics using (11). As mentioned earlier, if an LSTBC is of COD or GCOD codes, the ML decoding can be made separable for the $K$ symbols of $x_{k}$ so that only $M \cdot K$ metrics need to be computed [15]-[17]. Here, we investigate the possibility of this separability property for an LSTBC class wider than the COD and GCOD, whether orthogonal or nonorthogonal, i.e., the LSTBC with code matrices satisfying the broad conditions given in Section II. 
Substituting (3) into (11) and using (10), we obtain

$$
\begin{aligned}
D_{\mathrm{ML}}= & \sum_{q=1}^{Q}\left[\mathbf{r}_{q}^{H} \mathbf{r}_{q}-\mathbf{r}_{q}^{H} \mathbf{y}_{q}-\left(\mathbf{r}_{q}^{H} \mathbf{y}_{q}\right)^{H}+\mathbf{y}_{q}^{H} \mathbf{y}_{q}\right] \\
= & \sum_{q=1}^{Q} \mathbf{r}_{q}^{H} \mathbf{r}_{q}-\sum_{q=1}^{Q} \sum_{k=1}^{K}\left(\mathbf{r}_{q}^{H} \mathbf{A}_{k}^{T} \mathbf{h}_{q} x_{k c}+j \mathbf{r}_{q}^{H} \mathbf{B}_{k}^{T} \mathbf{h}_{q} x_{k s}\right) \\
& -\sum_{q=1}^{Q} \sum_{k=1}^{K}\left(\mathbf{r}_{q}^{H} \mathbf{A}_{k}^{T} \mathbf{h}_{q} x_{k c}+j \mathbf{r}_{q}^{H} \mathbf{B}_{k}^{T} \mathbf{h}_{q} x_{k s}\right)^{H} \\
& +\sum_{q=1}^{Q} \sum_{k=1}^{K} \mathbf{h}_{q}^{H}\left(x_{k c}^{2} \mathbf{W}_{k, 1}^{*}+x_{k s}^{2} \mathbf{W}_{k, 2}^{*}+x_{k c} x_{k s} \mathbf{W}_{k, 3}^{*}\right) \mathbf{h}_{q}
\end{aligned}
$$

where $\sum_{q=1}^{Q} \mathbf{r}_{q}^{H} \mathbf{r}_{q}$ is a common term for all $M^{K}$ metrics; thus, it can be discarded. The resulting metric can be written as

$$
D_{\mathrm{ML}}^{\prime}=\sum_{k=1}^{K} D_{\mathrm{ML}, k}
$$

where

$$
\begin{aligned}
D_{\mathrm{ML}, k}= & -\sum_{q=1}^{Q}\left(\mathbf{r}_{q}^{H} \mathbf{A}_{k}^{T} \mathbf{h}_{q} x_{k c}+j \mathbf{r}_{q}^{H} \mathbf{B}_{k}^{T} \mathbf{h}_{q} x_{k s}\right) \\
& -\sum_{q=1}^{Q}\left(\mathbf{r}_{q}^{H} \mathbf{A}_{k}^{T} \mathbf{h}_{q} x_{k c}+j \mathbf{r}_{q}^{H} \mathbf{B}_{k}^{T} \mathbf{h}_{q} x_{k s}\right)^{H} \\
& +\sum_{q=1}^{Q} \mathbf{h}_{q}^{H}\left(x_{k c}^{2} \mathbf{W}_{k, 1}^{*}+x_{k s}^{2} \mathbf{W}_{k, 2}^{*}+x_{k c} x_{k s} \mathbf{W}_{k, 3}^{*}\right) \mathbf{h}_{q} \\
= & -2 x_{k c} R_{k, 1}-2 x_{k s} R_{k, 2}+R_{k, 3}
\end{aligned}
$$

with $R_{k, 1}, R_{k, 2}$, and $R_{k, 3}$, respectively, defined as

$$
\begin{aligned}
R_{k, 1} & =\frac{1}{2} \sum_{q=1}^{Q}\left[\mathbf{r}_{q}^{H} \mathbf{A}_{k}^{T} \mathbf{h}_{q}+\left(\mathbf{r}_{q}^{H} \mathbf{A}_{k}^{T} \mathbf{h}_{q}\right)^{H}\right] \\
R_{k, 2} & =\frac{j}{2} \sum_{q=1}^{Q}\left[\mathbf{r}_{q}^{H} \mathbf{B}_{k}^{T} \mathbf{h}_{q}-\left(\mathbf{r}_{q}^{H} \mathbf{B}_{k}^{T} \mathbf{h}_{q}\right)^{H}\right] \\
R_{k, 3} & =\sum_{q=1}^{Q} \mathbf{h}_{q}^{H}\left(x_{k c}^{2} \mathbf{W}_{k, 1}^{*}+x_{k s}^{2} \mathbf{W}_{k, 2}^{*}+x_{k c} x_{k s} \mathbf{W}_{k, 3}^{*}\right) \mathbf{h}_{q} .
\end{aligned}
$$

It is apparent that $R_{k, 1}$ and $R_{k, 2}$ are real. Also, $R_{k, 3}$ is easily seen to be real due to the fact that $x_{k c}^{2} \mathbf{W}_{k, 1}^{*}+x_{k s}^{2} \mathbf{W}_{k, 2}^{*}+$ $x_{k c} x_{k s} \mathbf{W}_{k, 3}^{*}$ is Hermitian (the Hermitian of a real number is the real number itself). Thus, the metric $D_{\mathrm{ML}, k}$ of (14) is real, as it should be. In light of (13) and (14), we see that although the code may be nonorthogonal, the ML decoding of (11) can still be decoupled into $M \cdot K$ metrics, as given by (14). Thus, the simple ML decoupling is not the prerogative of the OSTBC.

However, the expression given by (14) is in an awkward form and, thus, is not convenient for analysis. We thus seek further refinement.
Observe that

$$
\begin{aligned}
\sum_{q=1}^{Q} \mathbf{h}_{q}^{H} \mathbf{W}_{k, 1}^{*} \mathbf{h}_{q} & =\sum_{q=1}^{Q} \mathbf{h}_{q}^{H} \mathbf{A}_{k}^{*} \mathbf{A}_{k}^{T} \mathbf{h}_{q} \\
& =\sum_{q=1}^{Q}\left(\mathbf{A}_{k}^{T} \mathbf{h}_{q}\right)^{H}\left(\mathbf{A}_{k}^{T} \mathbf{h}_{q}\right) \\
& =\sum_{q=1}^{Q}\left\|\mathbf{A}_{k}^{T} \mathbf{h}_{q}\right\|^{2}=\sum_{q=1}^{Q}\left\|\mathbf{a}_{k, q}\right\|^{2}=a_{k}^{2} \\
\sum_{q=1}^{Q} \mathbf{h}_{q}^{H} \mathbf{W}_{k, 2}^{*} \mathbf{h}_{q} & =\sum_{q=1}^{Q} \mathbf{h}_{q}^{H} \mathbf{B}_{k}^{*} \mathbf{B}_{k}^{T} \mathbf{h}_{q} \\
& =\sum_{q=1}^{Q}\left(\mathbf{B}_{k}^{T} \mathbf{h}_{q}\right)^{H}\left(\mathbf{B}_{k}^{T} \mathbf{h}_{q}\right)=\sum_{q=1}^{Q}\left\|\mathbf{B}_{k}^{T} \mathbf{h}_{q}\right\|^{2} \\
& =\sum_{q=1}^{Q}\left\|\mathbf{b}_{k, q}\right\|^{2}=\sum_{q=1}^{Q}\left\|j \mathbf{b}_{k, q}\right\|^{2} \\
& =\sum_{q=1}^{Q}\left\|\mathbf{b}_{k, q}^{\prime}\right\|^{2}=b_{k}^{2}
\end{aligned}
$$

where we have defined $\mathbf{a}_{k, q}=\mathbf{A}_{k}^{T} \mathbf{h}_{q}, \mathbf{b}_{k, q}=\mathbf{B}_{k}^{T} \mathbf{h}_{q}$, and $\mathbf{b}_{k, q}^{\prime}=j \mathbf{b}_{k, q}$. Also, observe that

$$
\begin{aligned}
& \sum_{q=1}^{Q} \mathbf{h}_{q}^{H} \mathbf{W}_{k, 3}^{*} \mathbf{h}_{q} \\
& \quad=-j \sum_{q=1}^{Q} \mathbf{h}_{q}^{H}\left(\mathbf{B}_{k}^{*} \mathbf{A}_{k}^{T}-\mathbf{A}_{k}^{*} \mathbf{B}_{k}^{T}\right) \mathbf{h}_{q} \\
& \quad=-j \sum_{q=1}^{Q}\left[\left(\mathbf{B}_{k}^{T} \mathbf{h}_{q}\right)^{H}\left(\mathbf{A}_{k}^{T} \mathbf{h}_{q}\right)-\left(\mathbf{A}_{k}^{T} \mathbf{h}_{q}\right)^{H}\left(\mathbf{B}_{k}^{T} \mathbf{h}_{q}\right)\right] \\
& \quad=\sum_{q=1}^{Q}\left[\left(j \mathbf{b}_{k, q}\right)^{H} \mathbf{a}_{k, q}+\mathbf{a}_{k, q}^{H}\left(j \mathbf{b}_{k, q}\right)\right] \\
& \quad=\sum_{q=1}^{Q}\left[\mathbf{b}_{k, q}^{\prime H} \mathbf{a}_{k, q}+\mathbf{a}_{k, q}^{H} \mathbf{b}_{k, q}^{\prime}\right]=2 c_{k} .
\end{aligned}
$$

Using (18)-(20), we can rewrite $R_{k, 3}$ as

$$
\begin{aligned}
R_{k, 3}= & x_{k c}^{2} \sum_{q=1}^{Q}\left\|\mathbf{a}_{k, q}\right\|^{2}+x_{k s}^{2} \sum_{q=1}^{Q}\left\|\mathbf{b}_{k, q}^{\prime}\right\|^{2} \\
& +x_{k c} x_{k s} \sum_{q=1}^{Q}\left[\mathbf{b}_{k, q}^{\prime H} \mathbf{a}_{k, q}+\mathbf{a}_{k, q}^{H} \mathbf{b}_{k, q}^{\prime}\right] \\
= & \sum_{q=1}^{Q}\left[\left\|x_{k c} \mathbf{a}_{k, q}\right\|^{2}+\left\|x_{k s} \mathbf{b}_{k, q}^{\prime}\right\|^{2}+\left(x_{k s} \mathbf{b}_{k, q}^{\prime}\right)^{H}\right. \\
& \left.\times\left(x_{k c} \mathbf{a}_{k, q}\right)+\left(x_{k c} \mathbf{a}_{k, q}\right)^{H}\left(x_{k s} \mathbf{b}_{k, q}^{\prime}\right)\right] \\
= & \sum_{q=1}^{Q}\left\|x_{k c} \mathbf{a}_{k, q}+x_{k s} \mathbf{b}_{k, q}^{\prime}\right\|^{2} \geq 0 .
\end{aligned}
$$


Another way to write $R_{k, 3}$ is

$$
\begin{aligned}
R_{k, 3} & =a_{k}^{2} x_{k c}^{2}+b_{k}^{2} x_{k s}^{2}+2 c_{k} x_{k c} x_{k s} \\
& =\left[\begin{array}{ll}
x_{k c} & x_{k s}
\end{array}\right]\left[\begin{array}{ll}
a_{k}^{2} & c_{k} \\
c_{k} & b_{k}^{2}
\end{array}\right]\left[\begin{array}{l}
x_{k c} \\
x_{k s}
\end{array}\right] .
\end{aligned}
$$

Since $R_{k, 3} \geq 0$, the $2 \times 2$ matrix in (22) is positive semidefinite and will have two real nonnegative eigenvalues given by

$$
\lambda_{k 1}, \lambda_{k 2}=\frac{1}{2}\left[a_{k}^{2}+b_{k}^{2} \pm \sqrt{\left(a_{k}^{2}-b_{k}^{2}\right)^{2}+4 c_{k}^{2}}\right] .
$$

The $2 \times 2$ matrix in (22) can be diagonalized by an orthogonal matrix as

$$
\left[\begin{array}{ll}
a_{k}^{2} & c_{k} \\
c_{k} & b_{k}^{2}
\end{array}\right]=\mathbf{U}_{k}\left[\begin{array}{cc}
\lambda_{k 1} & 0 \\
0 & \lambda_{k 2}
\end{array}\right] \mathbf{U}_{k}^{H}
$$

where $\mathbf{U}_{k}$ is the $2 \times 2$ orthogonal matrix whose columns consist of orthonormal eigenvectors corresponding to $\lambda_{k 1}, \lambda_{k 2}$, respectively. We can now use a linear transformation to obtain the following new set of symbols:

$$
\left[\begin{array}{ll}
x_{k c}^{\prime} & x_{k s}^{\prime}
\end{array}\right]=\left[\begin{array}{ll}
x_{k c} & x_{k s}
\end{array}\right] \mathbf{U}_{k} .
$$

Then, $R_{k, 3}$ takes a new form, i.e.,

$$
\begin{aligned}
R_{k, 3} & =\left[\begin{array}{ll}
x_{k c}^{\prime} & x_{k s}^{\prime}
\end{array}\right]\left[\begin{array}{cc}
\lambda_{k 1} & 0 \\
0 & \lambda_{k 2}
\end{array}\right]\left[\begin{array}{l}
x_{k c}^{\prime} \\
x_{k s}^{\prime}
\end{array}\right] \\
& =\lambda_{k 1} x_{k c}^{\prime 2}+\lambda_{k 2} x_{k s}^{\prime 2} .
\end{aligned}
$$

Now, the $k$ th ML metric of (14) can be rearranged to become

$$
\begin{aligned}
D_{\mathrm{ML}, k}= & -2 x_{k c} R_{k, 1}-2 x_{k s} R_{k, 2}+R_{k, 3} \\
= & -2\left[\begin{array}{ll}
x_{k c} & x_{k s}
\end{array}\right]\left[\begin{array}{l}
R_{k, 1} \\
R_{k, 2}
\end{array}\right]+R_{k, 3} \\
= & -2\left[\begin{array}{ll}
x_{k c} & x_{k s}
\end{array}\right] \mathbf{U}_{k} \mathbf{U}_{k}^{H}\left[\begin{array}{l}
R_{k, 1} \\
R_{k, 2}
\end{array}\right]+R_{k, 3} \\
= & -2\left[\begin{array}{ll}
x_{k c}^{\prime} & x_{k s}^{\prime}
\end{array}\right]\left[\begin{array}{l}
R_{k, 1}^{\prime} \\
R_{k, 2}^{\prime}
\end{array}\right]+R_{k, 3} \\
= & \frac{1}{\lambda_{k 1}}\left(R_{k, 1}^{\prime}-\lambda_{k 1} x_{k c}^{\prime}\right)^{2}+\frac{1}{\lambda_{k 2}}\left(R_{k, 2}^{\prime}-\lambda_{k 2} x_{k s}^{\prime}\right)^{2} \\
& -\left(\frac{R_{k, 1}^{\prime}}{\lambda_{k 1}}+\frac{R_{k, 2}^{\prime}}{\lambda_{k 2}}\right)
\end{aligned}
$$

where

$$
\left[\begin{array}{l}
R_{k, 1}^{\prime} \\
R_{k, 2}^{\prime}
\end{array}\right]=\mathbf{U}_{k}^{H}\left[\begin{array}{l}
R_{k, 1} \\
R_{k, 2}
\end{array}\right]
$$

In the last line of (27), the last parenthesis term contains no symbol terms $x_{k c}^{\prime}$ and $x_{k s}^{\prime}$ and is, hence, a common term. Thus, the minimization of (27) is equivalent to the minimizations of the following two metrics:

$$
\begin{aligned}
& D_{\mathrm{ML}, k c}=\left(R_{k, 1}^{\prime}-\lambda_{k 1} x_{k c}^{\prime}\right)^{2} \\
& D_{\mathrm{ML}, k s}=\left(R_{k, 2}^{\prime}-\lambda_{k 2} x_{k s}^{\prime}\right)^{2} .
\end{aligned}
$$

In light of (29a) and (29b), we can picture the system as formed by equivalent channels having virtual channel gains $\lambda_{k 1}, \lambda_{k 2}$ (functions of channel fading and code structure) and regard $x_{k c}^{\prime}, x_{k s}^{\prime}$ as the virtual transmitted signals and $R_{k, 1}^{\prime}, R_{k, 2}^{\prime}$ (functions of actual noisy received signals, channel fading, and code structure) as virtual noisy received signals. Then, (29a) and (29b) are nothing more than just the minimum distance metrics; thus, they are more informative than (14). In fact, $R_{k, 1}^{\prime}$, $R_{k, 2}^{\prime}$ contain more information. Referring back to (15) and (16), we see that $R_{k, 1}^{\prime}, R_{k, 2}^{\prime}$ are actually the respective outputs of two receiver linear processors and, hence, provide information for the design structures of the linear processors. Now, denoting the quantities in the two parentheses in (29a) and (29b) as $n_{k c}^{\prime}=R_{k, 1}^{\prime}-\lambda_{k 1} x_{k c}^{\prime}$ and $n_{k s}^{\prime}=R_{k, 2}^{\prime}-\lambda_{k 2} x_{k s}^{\prime}$, they can be regarded as the real and imaginary parts of the virtual complex noise, respectively. Using (24), (25), and (28), we have

$$
\begin{aligned}
{\left[\begin{array}{l}
n_{k c}^{\prime} \\
n_{k s}^{\prime}
\end{array}\right] } & =\left[\begin{array}{l}
R_{k, 1}^{\prime}-\lambda_{k 1} x_{k c}^{\prime} \\
R_{k, 2}^{\prime}-\lambda_{k 2} x_{k s}^{\prime}
\end{array}\right] \\
& =\mathbf{U}_{k}^{H}\left[\begin{array}{l}
R_{k, 1}-a_{k}^{2} x_{k c}-c_{k} x_{k s} \\
R_{k, 2}-c_{k} x_{k c}-b_{k}^{2} x_{k s}
\end{array}\right] .
\end{aligned}
$$

By applying (2)-(9) and (15) and (16), we can readily prove that (30) can be rewritten as

$$
\left[\begin{array}{c}
n_{k c}^{\prime} \\
n_{k s}^{\prime}
\end{array}\right]=\mathbf{U}_{k}^{H}\left[\begin{array}{c}
\frac{1}{2} \sum_{q=1}^{Q}\left[\mathbf{n}_{q}^{H} \mathbf{A}_{k}^{T} \mathbf{h}_{q}+\left(\mathbf{n}_{q}^{H} \mathbf{A}_{k}^{T} \mathbf{h}_{q}\right)^{H}\right] \\
\frac{j}{2} \sum_{q=1}^{Q}\left[\mathbf{n}_{q}^{H} \mathbf{B}_{k}^{T} \mathbf{h}_{q}-\left(\mathbf{n}_{q}^{H} \mathbf{B}_{k}^{T} \mathbf{h}_{q}\right)^{H}\right]
\end{array}\right]
$$

For fixed $\quad \mathbf{h}_{q}$, the terms $(1 / 2) \sum_{q=1}^{Q}\left[\mathbf{n}_{q}^{H} \mathbf{A}_{k}^{T} \mathbf{h}_{q}+\right.$ $\left.\left(\mathbf{n}_{q}^{H} \mathbf{A}_{k}^{T} \mathbf{h}_{q}\right)^{H}\right] \quad$ and $\quad(j / 2) \sum_{q=1}^{Q}\left[\mathbf{n}_{q}^{H} \mathbf{B}_{k}^{T} \mathbf{h}_{q}-\left(\mathbf{n}_{q}^{H} \mathbf{B}_{k}^{T} \mathbf{h}_{q}\right)^{H}\right]$ can be shown to be, respectively, Gaussian random variables (RVs) with zero mean and variances $\sigma_{k c}^{2}=a_{k}^{2} \sigma_{n}^{2} / 2$ and $\sigma_{k s}^{2}=b_{k}^{2} \sigma_{n}^{2} / 2$. Note that since the two variances are not equal, these Gaussian RVs are not identical. In view of (18) and (19), we see that $a_{k}^{2}$ and $b_{k}^{2}$ are both functions of the fading channel gain vector $\mathbf{h}_{q}$. Thus, with $\mathbf{h}_{q}$ being actually a random vector, $\sigma_{k c}^{2}$ and $\sigma_{k s}^{2}$ are, in fact, correlated RVs. From (31), when $\mathbf{h}_{q}$ is fixed, we see that $\left[\begin{array}{ll}n_{k c}^{\prime} & n_{k s}^{\prime}\end{array}\right]^{T}$ is a unitary rotation of a Gaussian vector with nonidentical RV components; thus, it remains as a Gaussian vector with nonidentical RV components. Therefore, we have an unusual case here. For the virtual system, the real and imaginary components $x_{k c}^{\prime}, x_{k s}^{\prime}$ of the $k$ th signal symbol will experience different channel gains $\lambda_{k 1}, \lambda_{k 2}$. Also, the real and imaginary noise components $n_{k c}^{\prime}$ and $n_{k s}^{\prime}$ are nonidentical Gaussian RVs (circularly nonsymmetric Gaussian RV [16]) and are generally correlated.

\section{ML Decoding for Various Special Cases}

Now, suppose that we allow $\mathbf{W}_{k, 3}=\mathbf{0}$. Then, various special cases can result.

Case 1: Without further condition relaxation, the condition $\mathbf{W}_{k, 3}=\mathbf{0}$ leads to $c_{k}=0$ and $\mathbf{U}_{k}=\mathbf{I}_{2}$ [see (24)]. The two 
eigenvalues are simply the equivalent channel gains, which are given as

$$
\begin{aligned}
& \lambda_{k 1}=a_{k}^{2}=\sum_{q=1}^{Q} \mathbf{h}_{q}^{H} \mathbf{W}_{k, 1}^{*} \mathbf{h}_{q}=\sum_{q=1}^{Q}\left\|\mathbf{A}_{k}^{T} \mathbf{h}_{q}\right\|^{2} \\
& \lambda_{k 2}=b_{k}^{2}=\sum_{q=1}^{Q} \mathbf{h}_{q}^{H} \mathbf{W}_{k, 2}^{*} \mathbf{h}_{q}=\sum_{q=1}^{Q}\left\|\mathbf{B}_{k}^{T} \mathbf{h}_{q}\right\|^{2} .
\end{aligned}
$$

Thus, $x_{k c}$ and $x_{k s}$ will experience unequal channel gains. As remarked in Section III, these gains $a_{k}^{2}$ and $b_{k}^{2}$ are correlated RVs. The two metrics of (29) become

$$
\begin{aligned}
& D_{\mathrm{ML}, k c}=\left(R_{k, 1}-a_{k}^{2} x_{k c}\right)^{2} \\
& D_{\mathrm{ML}, k s}=\left(R_{k, 2}-b_{k}^{2} x_{k s}\right)^{2} .
\end{aligned}
$$

By applying (2)-(9) and (15), (16), and (32) along with $\mathbf{W}_{k, 3}=$ $\mathbf{0}$ onto (33), we can readily show that the two noise components $R_{k, 1}-a_{k}^{2} x_{k c}$ and $R_{k, 2}-b_{k}^{2} x_{k s}$ can be expressed as

$$
\begin{aligned}
n_{k c} & =R_{k, 1}-a_{k}^{2} x_{k c} \\
& =\frac{1}{2} \sum_{q=1}^{Q}\left[\mathbf{n}_{q}^{H} \mathbf{A}_{k}^{T} \mathbf{h}_{q}+\left(\mathbf{n}_{q}^{H} \mathbf{A}_{k}^{T} \mathbf{h}_{q}\right)^{H}\right] \\
n_{k s} & =R_{k, 2}-b_{k}^{2} x_{k s} \\
& =\frac{j}{2} \sum_{q=1}^{Q}\left[\mathbf{n}_{q}^{H} \mathbf{B}_{k}^{T} \mathbf{h}_{q}-\left(\mathbf{n}_{q}^{H} \mathbf{B}_{k}^{T} \mathbf{h}_{q}\right)^{H}\right] .
\end{aligned}
$$

We have already shown that for fixed channel realizations, these two noise components are nonidentical Gaussian RVs with zero mean and variances $\sigma_{k c}^{2}=a_{k}^{2} \sigma_{n}^{2} / 2$ and $\sigma_{k s}^{2}=b_{k}^{2} \sigma_{n}^{2} / 2$, respectively. It should be noted here that although $\mathbf{W}_{k, 3}=\mathbf{0}$, we still have a nonorthogonal code if $\mathbf{W}_{k, 1}$ and $\mathbf{W}_{k, 2}$ are not diagonal matrices.

Case 2: In addition to $\mathbf{W}_{k, 3}=\mathbf{0}$, if $\mathbf{W}_{k, 1}=\mathbf{W}_{k, 2}$ (this means $a_{k}^{2}=b_{k}^{2}$ but not $R_{k, 1}=R_{k, 2}$ ), we have a circularly symmetric situation. That is, $x_{k c}$ and $x_{k s}$ will experience equal channel gains, and the equivalent noise is a circularly symmetric Gaussian RV $\left[n_{k c}\right.$ and $n_{k s}$ are independent identically distributed (i.i.d.)]. Again, if $\mathbf{W}_{k, 1}$ and $\mathbf{W}_{k, 2}$ are not diagonal matrices, the code is nonorthogonal.

Case 3: In addition to $\mathbf{W}_{k, 3}=\mathbf{0}$, we further let $\mathbf{W}_{k, 1}=$ $\boldsymbol{\Lambda}_{k, 1}$ and $\mathbf{W}_{k, 2}=\boldsymbol{\Lambda}_{k, 2}$, where $\boldsymbol{\Lambda}_{k, 1}$ and $\boldsymbol{\Lambda}_{k, 2}$ are diagonal matrices of the following forms:

$$
\begin{aligned}
\boldsymbol{\Lambda}_{k, 1} & =\left[\begin{array}{cccc}
\alpha_{k 1} & 0 & \cdots & 0 \\
0 & \ddots & & \vdots \\
\vdots & & \ddots & 0 \\
0 & \cdots & 0 & \alpha_{k P}
\end{array}\right] \\
\boldsymbol{\Lambda}_{k, 2} & =\left[\begin{array}{cccc}
\beta_{k 1} & 0 & \cdots & 0 \\
0 & \ddots & & \vdots \\
\vdots & & \ddots & 0 \\
0 & \cdots & 0 & \beta_{k P}
\end{array}\right] .
\end{aligned}
$$

Thus, for this orthogonal code, both noise components $n_{k c}$ and $n_{k s}$ also have different variances and, hence, are not identical.

Case 4: If in Case 3, we let $\boldsymbol{\Lambda}_{k, 1}=\boldsymbol{\Lambda}_{k, 2}=\boldsymbol{\Lambda}_{k}$, then $\alpha_{k p}=$ $\beta_{k p}$. The metrics for the real and imaginary symbol components become

$$
\begin{aligned}
D_{\mathrm{ML}, k c} & =\left(R_{k, 1}-x_{k c} \sum_{q=1}^{Q} \sum_{p=1}^{P} \alpha_{k p}\left|h_{p, q}\right|^{2}\right)^{2} \\
D_{\mathrm{ML}, k s} & =\left(R_{k, 2}-x_{k s} \sum_{q=1}^{Q} \sum_{p=1}^{P} \alpha_{k p}\left|h_{p, q}\right|^{2}\right)^{2} .
\end{aligned}
$$

This is equivalent to an order $P \times Q$ maximal ratio combining (MRC) system with channel gains $\left\{\sqrt{\alpha_{k p}} h_{p, q}\right\}$. In addition, 
$n_{k c}$ and $n_{k s}$ are now i.i.d. Gaussian RVs with zero mean and the same variance (circularly symmetric Gaussian) given by

$$
\sigma_{k c}^{2}=\sigma_{k s}^{2}=\frac{\sigma_{n}^{2}}{2} \sum_{q=1}^{Q} \sum_{p=1}^{P} \alpha_{k p}\left|h_{p, q}\right|^{2} .
$$

Note that from (10), we have in this case

$$
\mathbf{G G}^{H}=\sum_{k=1}^{K}\left|x_{k}\right|^{2} \boldsymbol{\Lambda}_{k}
$$

which is a $P \times P$ diagonal matrix with the $(p, p)$ th diagonal element $\sum_{k=1}^{K} \alpha_{k p}\left|x_{k}\right|^{2}$. Thus, we have here a GCOD system [5], [14], [17]. In fact, (40a) and (40b) together are equivalent to the result given in [17]. However, our derivation here deduced from the broad conditions is short and concise.

Case 5: If, in Case 4, we further relax the condition to $\boldsymbol{\Lambda}_{k}=\mathbf{I}_{P}$, then $\alpha_{k p}=\beta_{k p}=1$. The two metrics can then be simplified as

$$
\begin{aligned}
D_{\mathrm{ML}, k c} & =\left(R_{k, 1}-x_{k c} \sum_{q=1}^{Q} \sum_{p=1}^{P}\left|h_{p, q}\right|^{2}\right)^{2} \\
& =\left(R_{k, 1}-x_{k c} \sum_{q=1}^{Q}\left\|\mathbf{h}_{q}\right\|^{2}\right)^{2} \\
D_{\mathrm{ML}, k s} & =\left(R_{k, 2}-x_{k s} \sum_{q=1}^{Q} \sum_{p=1}^{P}\left|h_{p, q}\right|^{2}\right)^{2} \\
& =\left(R_{k, 2}-x_{k s} \sum_{q=1}^{Q}\left\|\mathbf{h}_{q}\right\|^{2}\right)^{2} .
\end{aligned}
$$

This is equivalent to an order $P \times Q$ MRC system with channel gains $\left\{h_{p, q}\right\}$. In addition, $n_{k c}$ and $n_{k s}$ are i.i.d. Gaussian RVs with zero mean and the same variance (circularly symmetric Gaussian) given by

$$
\sigma_{k c}^{2}=\sigma_{k s}^{2}=\frac{\sigma_{n}^{2}}{2} \sum_{q=1}^{Q} \sum_{p=1}^{P}\left|h_{p, q}\right|^{2} .
$$

Also, we have

$$
\mathbf{G G}^{H}=\sum_{k=1}^{K}\left|x_{k}\right|^{2} \mathbf{I}_{P}
$$

Thus, we have here a COD system [5], [10]. Also, (43a) and (43b) together are equivalent to the result given in [15]. Again, our derivation is obviously short and concise, as compared to that given in [15].

From the aforementioned, we see that the OSTBC (Cases 4 and 5) is a subclass of the more general class of LSTBC discussed here. The rest of the cases (Cases 1-3) have not been given research attention. However, it does not mean that they do not exist or will never be developed. In fact, as mentioned earlier, some nonorthogonal codes that belong to Case 2 have recently appeared in the literature [18]-[20]. In Section V, we will present such a code following the technique given in [19] as a demonstration. Without a doubt, a more systematic method for the construction of the code class of LSTBC discussed in this paper needs be explored. This may be a challenging problem. Even for the much familiar OSTBC, a more thorough code construction method is still needed. The main purpose of this paper is to show that when codes that fall into the LSTBC class under discussion can be made available, we show that, whether the codes are orthogonal or nonorthogonal, they can be decoded by ML metric decoupling through receiver linear processing, hence pointing out that ML decoupling is not the prerogative of only the OSTBC.

\section{NUMERICAL EXAMPLE OF A NONORTHOGONAL LSTBC}

In this section, we show an example of a nonorthogonal LSTBC that falls into the class of LSTBC discussed in this paper. We use the optimum precoding method given in [19]. We start with the following COD OSTBC given in [8]:

$$
\mathbf{G}=\left[\begin{array}{cccc}
-x_{3} & 0 & x_{1}^{*} & x_{2}^{*} \\
-x_{2} & x_{1}^{*} & 0 & -x_{3}^{*} \\
x_{1} & x_{2}^{*} & x_{3}^{*} & 0
\end{array}\right]
$$

This code uses $P=3$ transmit antennas to transmit $K=3$ symbols over a block of $N=4$ time slots. For simplicity, we will use a single receive antenna $(Q=1)$. Thus, the order of diversity is $L=P Q=3$. Consider correlated Rayleigh fading channels with the channel power ratio $\sigma_{h_{1}}^{2}: \sigma_{h_{2}}^{2}: \sigma_{h_{3}}^{2}=1: 1: 0.6$, where $\sigma_{h_{l}}^{2}=E\left[\left|h_{l}\right|^{2}\right], l=1,2,3$. According to [19], a new code can be formed by precoding $\mathbf{G}$ as

$$
\mathbf{C}=\left(\mathbf{D}_{f} \mathbf{U}_{h}^{H}\right)^{T} \mathbf{G}
$$

where $\mathbf{U}_{h}$ is the orthogonal matrix that diagonalizes the channel covariance matrix $\mathbf{R}_{h h}=E\left[\mathbf{h h}^{H}\right]$, with $\mathbf{h}=$ $\left[h_{1}, h_{2}, \ldots, h_{L}\right]$ being the $L \times 1$ channel vector formed by stacking $\left\{h_{p, q}\right\}, L=P Q$, and $\mathbf{D}_{f}$, which is a function of the signal-to-noise ratio (SNR), is a diagonal matrix whose diagonal elements are obtained by optimum power loading [19, eq. (30)]. We assume a constant channel correlation model [21]. Constant correlation can be obtained by a circularly symmetric three-element antenna array with close spacing between elements [21]. This constant correlation case has been used in [21] for an order-3 MRC diversity over Nakagami fading. For the order-3 transmit diversity with constant channel correlation, the channel covariance matrix is given by

$$
\mathbf{R}_{h h}=\left[\begin{array}{ccc}
\sigma_{h_{1}}^{2} & \sigma_{h_{1}} \sigma_{h_{2}} \rho & \sigma_{h_{1}} \sigma_{h_{3}} \rho \\
\sigma_{h_{1}} \sigma_{h_{2}} \rho & \sigma_{h_{2}}^{2} & \sigma_{h_{2}} \sigma_{h_{3}} \rho \\
\sigma_{h_{1}} \sigma_{h_{3}} \rho & \sigma_{h_{2}} \sigma_{h_{3}} \rho & \sigma_{h_{3}}^{2}
\end{array}\right]
$$

where $\rho$ is the constant correlation coefficient between any pair of the three channels. For the aforementioned channel 
power ratio, assuming $\rho=0.6$, the orthogonal matrix $\mathbf{U}_{h}$ can be readily calculated as

$$
\mathbf{U}_{h}=\left[\begin{array}{ccc}
-0.6335 & 0.7071 & -0.3141 \\
-0.6335 & -0.7071 & -0.3141 \\
-0.4442 & 0 & 0.8959
\end{array}\right]
$$

Then, assuming that the average received SNR per channel is $20 \mathrm{~dB}, \mathbf{D}_{f}$ can be computed as

$$
\mathbf{D}_{f}=\left[\begin{array}{ccc}
0.6935 & 0 & 0 \\
0 & 0.5561 & 0 \\
0 & 0 & 0.4580
\end{array}\right]
$$

while the average received SNR per channel is defined as $(1 / L) \sum_{l=1}^{L} E\left(\left|h_{l}\right|^{2}\right) E\left(\left|x_{k}\right|^{2}\right) / \sigma_{n}^{2}$. Using (47), we find

$$
\begin{aligned}
& \mathbf{C}=\left[\mathbf{c}_{1} \mathbf{c}_{2} \mathbf{c}_{3} \mathbf{c}_{4}\right] \\
& \mathbf{c}_{1}=\left[\begin{array}{c}
-0.1439 x_{1}-0.3932 x_{2}+0.4393 x_{3} \\
-0.1439 x_{1}+0.3932 x_{2}+0.4393 x_{3} \\
0.4103 x_{1}+0.3081 x_{3}
\end{array}\right] \\
& \mathbf{c}_{2}=\left[\begin{array}{c}
0.3932 x_{1}^{*}-0.1439 x_{2}^{*} \\
-0.3932 x_{1}^{*}-0.1439 x_{2}^{*} \\
0.4103 x_{2}^{*}
\end{array}\right] \\
& \mathbf{c}_{3}=\left[\begin{array}{c}
-0.4393 x_{1}^{*}-0.1439 x_{3}^{*} \\
-0.4393 x_{1}^{*}-0.1439 x_{3}^{*} \\
-0.3081 x_{1}^{*}+0.4103 x_{3}^{*}
\end{array}\right] \\
& \mathbf{c}_{4}=\left[\begin{array}{c}
-0.4393 x_{2}^{*}-0.3932 x_{3}^{*} \\
-0.4393 x_{2}^{*}+0.3932 x_{3}^{*} \\
-0.3081 x_{2}^{*}
\end{array}\right] .
\end{aligned}
$$

Then, using (47), (49), and (50), we find

$$
\begin{aligned}
\mathbf{C C}^{H} & =\left(\mathbf{D}_{f} \mathbf{U}_{h}^{H}\right)^{T} \mathbf{G G}^{H}\left(\mathbf{D}_{f} \mathbf{U}_{h}^{H}\right)^{*} \\
& =\sum_{k=1}^{3}\left|x_{k}\right|^{2} \mathbf{U}_{h}^{*} \mathbf{D}_{f}^{2} \mathbf{U}_{h}^{T} \\
& =\sum_{k=1}^{3}\left|x_{k}\right|^{2}\left[\begin{array}{lll}
0.3683 & 0.0591 & 0.0763 \\
0.0591 & 0.3683 & 0.0763 \\
0.0763 & 0.0763 & 0.2633
\end{array}\right] .
\end{aligned}
$$

Since the matrix in (52) is not diagonal, $\mathbf{C}$ is a nonorthogonal LSTBC. In fact, $\mathbf{C}$ belongs to Case 2, as given in Section IV. However, as analyzed in [19], this nonorthogonal $\mathbf{C}$ will yield a lower SER than the orthogonal $\mathbf{G}$ for the same SNR. We will not repeat here the analysis of SER performance as our main subject is to prove the ML decoupling capability of the LSTBC.

Next, we want to design the receiver linear processors. Similar to (2), we may have

$$
\mathbf{C}=\sum_{k=1}^{K}\left(x_{k c} \mathbf{A}_{k}^{\mathrm{C}}+j x_{k s} \mathbf{B}_{k}^{\mathrm{C}}\right)
$$

From (53), it is relatively easy to find

$$
\begin{aligned}
& \mathbf{A}_{1}^{C}=\left[\begin{array}{cccc}
-0.1439 & 0.3932 & -0.4393 & 0 \\
-0.1439 & -0.3932 & -0.4393 & 0 \\
0.4103 & 0 & -0.3081 & 0
\end{array}\right] \\
& \mathbf{A}_{2}^{\mathrm{C}}=\left[\begin{array}{cccc}
-0.3932 & -0.1439 & 0 & -0.4393 \\
0.3932 & -0.1439 & 0 & -0.4393 \\
0 & 0.4103 & 0 & -0.3081
\end{array}\right] \\
& \mathbf{A}_{3}^{\mathrm{C}}=\left[\begin{array}{cccc}
0.4393 & 0 & -0.1439 & -0.3932 \\
0.4393 & 0 & -0.1439 & 0.3932 \\
0.3081 & 0 & 0.4103 & 0
\end{array}\right] \\
& \mathbf{B}_{1}^{\mathrm{C}}=\left[\begin{array}{cccc}
-0.1439 & -0.3932 & 0.4393 & 0 \\
-0.1439 & 0.3932 & 0.4393 & 0 \\
0.4103 & 0 & 0.3081 & 0
\end{array}\right] \\
& \mathbf{B}_{2}^{\mathrm{C}}=\left[\begin{array}{cccc}
-0.3932 & 0.1439 & 0 & 0.4393 \\
0.3932 & 0.1439 & 0 & 0.4393 \\
0 & -0.4103 & 0 & 0.3081
\end{array}\right] \\
& \mathbf{B}_{3}^{\mathrm{C}}=\left[\begin{array}{cccc}
0.4393 & 0 & 0.1439 & 0.3932 \\
0.4393 & 0 & 0.1439 & -0.3932 \\
0.3081 & 0 & -0.4103 & 0
\end{array}\right] .
\end{aligned}
$$

Now, applying (15) and (16), we obtain the linear processors as follows:

$$
\begin{aligned}
R_{1,1}=\operatorname{Re}[ & h_{1,1}\left(-0.1439 r_{1,1}^{*}+0.3932 r_{2,1}^{*}-0.4393 r_{3,1}^{*}\right) \\
+ & h_{2,1}\left(-0.1439 r_{1,1}^{*}-0.3932 r_{2,1}^{*}-0.4393 r_{3,1}^{*}\right) \\
+ & \left.h_{3,1}\left(0.4103 r_{1,1}^{*}-0.3081 r_{3,1}^{*}\right)\right] \\
R_{2,1}=\operatorname{Re}[ & h_{1,1}\left(-0.3932 r_{1,1}^{*}-0.1439 r_{2,1}^{*}-0.4393 r_{4,1}^{*}\right) \\
+ & h_{2,1}\left(0.3932 r_{1,1}^{*}-0.1439 r_{2,1}^{*}-0.4393 r_{4,1}^{*}\right) \\
+ & \left.h_{3,1}\left(0.4103 r_{2,1}^{*}-0.3081 r_{4,1}^{*}\right)\right] \\
R_{3,1}=\operatorname{Re}[ & h_{1,1}\left(0.4393 r_{1,1}^{*}-0.1439 r_{3,1}^{*}-0.3932 r_{4,1}^{*}\right) \\
+ & h_{2,1}\left(0.4393 r_{1,1}^{*}-0.1439 r_{3,1}^{*}+0.3932 r_{4,1}^{*}\right) \\
+ & \left.h_{3,1}\left(0.3081 r_{1,1}^{*}+0.4103 r_{3,1}^{*}\right)\right] \\
R_{1,2}=-\operatorname{Im}[ & h_{1,1}\left(-0.1439 r_{1,1}^{*}-0.3932 r_{2,1}^{*}+0.4393 r_{3,1}^{*}\right) \\
& +h_{2,1}\left(-0.1439 r_{1,1}^{*}+0.3932 r_{2,1}^{*}+0.4393 r_{3,1}^{*}\right) \\
& \left.+h_{3,1}\left(0.4103 r_{1,1}^{*}+0.3081 r_{3,1}^{*}\right)\right] \\
R_{2,2}=-\operatorname{Im}[ & h_{1,1}\left(-0.3932 r_{1,1}^{*}+0.1439 r_{2,1}^{*}+0.4393 r_{4,1}^{*}\right) \\
& +h_{2,1}\left(0.3932 r_{1,1}^{*}+0.1439 r_{2,1}^{*}+0.4393 r_{4,1}^{*}\right) \\
+ & \left.h_{3,1}\left(-0.4103 r_{2,1}^{*}+0.3081 r_{4,1}^{*}\right)\right] \\
R_{3,2}=-\operatorname{Im}[ & h_{1,1}\left(0.4393 r_{1,1}^{*}+0.1439 r_{3,1}^{*}+0.3932 r_{4,1}^{*}\right) \\
& +h_{2,1}\left(0.4393 r_{1,1}^{*}+0.1439 r_{3,1}^{*}-0.3932 r_{4,1}^{*}\right) \\
& \left.+h_{3,1}\left(0.3081 r_{1,1}^{*}-0.4103 r_{3,1}^{*}\right)\right] .
\end{aligned}
$$

To save space, we will only present the ML decoding for the estimate $\hat{x}_{1}$. Using (4), (5), (54), and (55), we find

$$
\begin{aligned}
\mathbf{W}_{k, 1}^{\mathrm{C}} & =\mathbf{A}_{k}^{\mathrm{C}} \mathbf{A}_{k}^{\mathrm{C}^{H}}=\mathbf{B}_{k}^{\mathrm{C}} \mathbf{B}_{k}^{\mathrm{C}^{H}}=\mathbf{W}_{k, 2}^{\mathrm{C}} \\
& =\left[\begin{array}{lll}
0.3683 & 0.0591 & 0.0763 \\
0.0591 & 0.3683 & 0.0763 \\
0.0763 & 0.0763 & 0.2633
\end{array}\right] \\
\mathbf{W}_{k, 3}^{\mathrm{C}} & =\mathbf{0} .
\end{aligned}
$$


We see that this code belongs to Case 2. Then, using (32), we find

$$
\begin{aligned}
a_{1}^{2}= & b_{1}^{2} \\
= & 0.3683\left|h_{1,1}\right|^{2}+0.3683\left|h_{2,1}\right|^{2}+0.2633\left|h_{3,1}\right|^{2} \\
& +2 \operatorname{Re}\left[0.0591 h_{1,1}^{*} h_{2,1}+0.0763 h_{2,1}^{*} h_{3,1}\right. \\
& \left.\quad+0.0763 h_{3,1}^{*} h_{1,1}\right] .
\end{aligned}
$$

Now, substituting $R_{1,1}$ and $R_{1,2}$ from (56) and $a_{1}^{2}=b_{1}^{2}$ from (58) into (33), we obtain the ML decoding for the estimate $\hat{x}_{1}$. Computing (33) using $\left\{x_{m c}, x_{m s}, m=0,1, \ldots, M-1\right\}$ and choosing the smallest metrics of (33), we obtain the ML estimate $\hat{x}_{1}$. It is evident that using (33), the linear processing receiver can be readily implemented.

\section{CONCLUSION}

We have introduced and formulated a general class of LSTBC that encompasses orthogonal and nonorthogonal codes. Then, we derive decoupled ML metric expressions for these codes, thus proving that the ML decoupling is not the prerogative of only the orthogonal codes. A by-product of our derivations is the design information for the receiver linear processor structure that is automatically contained in the decoupled ML metric expressions. Although many nonorthogonal codes that fall into our general class have yet to be discovered, there exist some nonorthogonal codes that indeed fall into the class. We show an example of the nonorthogonal LSTBC that appears in the recent literature and present the receiver design. What is encouraging is that when fading channels are correlated, nonorthogonal codes can be generated to outperform orthogonal codes in terms of error rate performance. Some of the codes presented here have the rare properties that channel gains for the real and imaginary parts of signal symbols are unequal and that the additive complex Gaussian noise is not circularly symmetric. These properties should make the problems more challenging.

\section{REFERENCES}

[1] S. M. Alamouti, "A simple transmit diversity technique for wireless communications," IEEE J. Sel. Areas Commun., vol. 16, no. 8, pp. 1451-1458, Oct. 1998.

[2] W. Su and X.-G. Xia, "On space-time block codes from complex orthogonal designs," Wirel. Pers. Commun., vol. 25, no. 1, pp. 1-26, Apr. 2003.

[3] V. Tarokh, N. Seshadri, and A. R. Calderbank, "Space-time codes for high data rate wireless communication: Performance criterion and code construction," IEEE Trans. Inf. Theory, vol. 44, no. 2, pp. 744-765, Mar. 1998.

[4] V. Tarokh, H. Jafarkhani, and A. R. Calderbank, "Space-time block coding for wireless communications: Performance results," IEEE J. Sel. Areas Commun., vol. 17, no. 3, pp. 451-460, Mar. 1999.

[5] V. Tarokh, H. Jafarkhani, and A. R. Calderbank, "Space-time block codes from orthogonal designs," IEEE Trans. Inf. Theory, vol. 45, no. 5, pp. 1456-1467, Jul. 1999.

[6] S. Sandhu and A. Paulraj, "Space-time block codes: A capacity perspective," IEEE Commun. Lett., vol. 4, no. 12, pp. 384-386, Dec. 2000.

[7] G. Ganesan and P. Stoica, "Space-time block codes: A maximum SNR approach," IEEE Trans. Inf. Theory, vol. 47, no. 4, pp. 1650-1656, May 2001.

[8] B. Hochwald, T. L. Marzetta, and C. B. Papadias, "A transmitter diversity scheme for wideband CDMA systems based on space-time spreading," IEEE J. Sel. Areas Commun., vol. 19, no. 1, pp. 48-60, Jan. 2001.
[9] X.-B. Liang, "A high-rate orthogonal space-time block code," IEEE Commun. Lett., vol. 7, no. 5, pp. 222-223, May 2003.

[10] L. C. Tran, J. Seberry, Y. Wang, B. J. Wysocki, T. A. Wysocki, T. Xia, and Y. Zhao, "Two complex orthogonal space-time codes for eight transmit antennas," Electron. Lett., vol. 40, no. 1, pp. 55-57, Jan. 2004.

[11] X.-B. Liang, "Orthogonal designs with maximal rates," IEEE Trans. Inf. Theory, vol. 49, no. 10, pp. 2468-2503, Oct. 2003.

[12] K. Lu, S. Fu, and X.-G. Xia, "Closed-form designs of complex orthogonal space-time block codes of rates $(k+1) /(2 k)$ for $2 k-1$ or $2 k$ transmit antennas," IEEE Trans. Inf. Theory, vol. 51, no. 12, pp. 4340-4347, Dec. 2005.

[13] X.-B. Liang, "A complex orthogonal space-time block code for 8 transmit antennas," IEEE Commun. Lett., vol. 9, no. 2, pp. 115-117, Feb. 2005.

[14] W. Su and X.-G. Xia, "Two generalized complex orthogonal space-time block codes of rates 7/11 and 3/5 for 5 and 6 transmit antennas," IEEE Trans. Inf. Theory, vol. 49, no. 1, pp. 313-316, Jan. 2003.

[15] X. Li, T. Lau, G. Yue, and C. Yin, "A squaring method to simplify the decoding of orthogonal space-time block codes," IEEE Trans. Commun., vol. 49, no. 10, pp. 1700-1703, Oct. 2001.

[16] E. G. Larsson and P. Stoica, Space-Time Block Coding for Wireless Communications. New York: Cambridge Univ. Press, 2003.

[17] C. Xu and K. S. Kwak, "On decoding algorithm and performance of space-time block codes," IEEE Trans. Wireless Commun., vol. 4, no. 3, pp. 825-829, May 2005.

[18] G. Jongren, M. Skoglund, and B. Ottersten, "Combining beamforming and orthogonal space-time block coding," IEEE Trans. Inf. Theory, vol. 48, no. 3, pp. 611-627, Mar. 2002.

[19] S. Zhou and G. B. Giannakis, "Optimal transmitter eigen-beamforming and space-time block coding based on channel correlations," IEEE Trans. Inf. Theory, vol. 49, no. 7, pp. 1673-1690, Jul. 2003.

[20] A. Hjorungnes, D. Gesbert, and J. Akhtar, "Precoding of space-time block coded signals for joint transmit-receive correlated MIMO channels," IEEE Trans. Wireless Commun., vol. 5, no. 3, pp. 492-497, Mar. 2006.

[21] V. A. Aalo, "Performance of maximal-ratio diversity systems in a correlated Nakagami-fading environment," IEEE Trans. Commun., vol. 43 , no. 8, pp. 2360-2369, Aug. 1995.

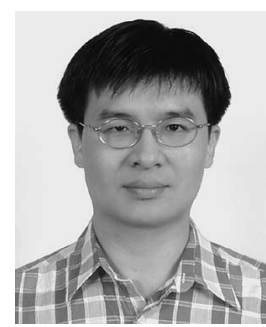

Hong-Yu Liu received the M.S. degree in electrical engineering from the National Cheng Kung University, Tainan, Taiwan, R.O.C., in 1994 and the $\mathrm{Ph} . \mathrm{D}$. degree in electrical engineering from Tamkang University, Taipei, Taiwan, in 2006.

Since 1998, he has been with the faculty of the Department of Computer and Communication Engineering, Dahan Institute of Technology, Hualien, Taiwan, where he is currently an Associate Professor. His research interests are in the areas of adaptive filtering, multiuser detection, channel estimation, and

space-time coding.

Dr. Liu was elected as an Honorary Member of the Phi Tau Phi Scholastic Honor Society, R.O.C., in 2006.

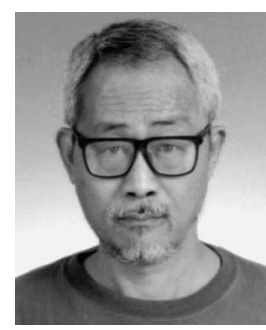

Rainfield Y. Yen received the B.S. degree from the National Taiwan University, Taipei, Taiwan, R.O.C., in 1966, the M.S. degree from Washington State University, Pullman, in 1968, and the Ph.D. degree from Columbia University, New York, NY, in 1972, all in electrical engineering.

In 1972, he joined TRW, Washington Operation, as a Member of Technical Staff, where he worked in the area of sonar signal processing, adaptive beamforming, and underwater countermeasure system engineering. In 1984, he joined Tamkang University, Taipei, where he is currently a Professor of electrical engineering. His research interests include channel equalization, antenna diversity, OFDM, and space-time block coding. 
本計畫執行期間共有兩篇相關論文刊登於國際知名 SCI 期刊 [1]-[2], 並積極參與國際 性與全國性學術研討會以接軌於國際, 充分與國内外學者交流, 見於 [3]-[5]。

[1]Rainfield Y. Yen, Hong-Yu Liu, and W. K. Tsai, "QAM symbol error rate in OFDM systems over frequency-selective fast Ricean fading channels," IEEE Transactions on Vehicular Technology, vol. 57, no. 2, pp. 954-961, Mar. 2008.

[2]Hong-Yu Liu and Rainfield Y. Yen, "Maximum-Likelihood Decoding for Non-Orthogonal and Orthogonal Linear Space-Time Block Codes," IEEE Transactions on Vehicular Technology, vol. 57, no. 2, pp. 1322-1325, Mar. 2008.

[3]Rainfield Y. Yen, Young-Ming Hwa, Shang-Chieh Nan, Kuo-Feng Yang, Ming-Chih Hong, and Hong-Yu Liu, "Application of a novel maximum-likelihood algorithm to the estimation of signal propagation delay in an optical fiber link" National Symposium on Telecommunications (NST 2007), Taipei, Taiwan, Nov. 23-24, 2007, pp. 647-650.

[4]Rainfield Y. Yen, Hong-Yu Liu, Chun-Chi Lee, Shang-Chieh Nan, and Ming-Chih Hong, "Performance of a non-orthogonal STBC over correlative fading channels," The Second IEEE International Conference on Communications and Electronics (HUT-ICCE 2008), Hoi An, Vietnam, June 4-6, 2008, pp.272-277.

[5] Rainfield Y. Yen, Hong-Yu Liu , Kuo-Feng Yang, Ming-Chih Hong, and Shang-Chieh Nan, "Optimum training sequence design based on maximum-likelihood channel estimation in OFDM systems over frequency-selective channels," The fourth National Workshop on Internet and Communication Technology (NWICT2008), Tamsui, Taipei, Taiwan, April 16, 2008, pp.281-286. 


\section{計畫成果自評}

本計畫執行的成果為非常卓越, 一如” 參考文獻” 中所示, 共兩篇論文 [1][2]已刊登 於國際知名 SCI 期刊 IEEE Transactions on Vehicular Technology, 並多次參與國内外 知名之學術研討會 [3]-[5], 其中於越南舉辦之 HUT-ICCE 2008 研討會 [4]為 IEEE 所主辦 的，發表之文章將收錄於 I E E E 電子資料庫 IEL 中；發表於台北科技大學的 NST2007[3] 為國内一年一度全國電信研討會, 集合國内電信領域之專家、學者與先進, 共同分享最新 研究之成果; 而於聖約翰科大舉辦的 NWICT 2008[5], 則每年之參與人數與發表論文數量 都高度成長, 逐漸成為國內電子與資訊領域之重要學術會議之一。

非常成功地對於時空區塊碼, 從最基礎的 Alamouti 雙傳輸天線之正交時空區塊碼, 到 非正交的一般化線性時空區塊碼, 都做了詳盡且徹底的分析與設計 [2][4]。於學術與業界, 不謹提出嚴謹且傑出的理論, 並對未來實務通訊系統規格之訂定, 指出另一條極可行的發 展方向, 特別是考虑到具相關性衰退通道時之系統特性 [4]。研究成果亦依規劃, 推展至時 間一頻率領域的 OFDM 系統, 考慮快速時變通道下的性能分析 [1], 並且推廣至一般化的雷利 衰退通道。更重要的是, 我們指出傳統文獻中對錯誤率分析之不精確的假設條件, 以致與 實際有所誤差之處, 並提出數學分析證明之。此外, O F D M 接收機的訓練序列設計亦被 討論 $[5]$, 成功建立最佳訓練序列之數學理論。

本研究計畫成果不僅應用於無線通訊領域 $[1][2][4][5]$, 也旁觸及近年快速發展光纖 通訊系統中 [3], 利用先進之數位訊號處理技術, 提昇光繊通訊系統的傳輸效能, 取代昂 貴之光元件或設備, 也就是計畫成果顯然超越預期。

計畫成果的展現從非正交時空區塊碼的分析與設計開始, 考慮的通道模型為最一般 化, 並且成功的將通道相關性考虑進去, 而仍保有精簡的系統化分析公式。此一研究方法 亦被成功地運用於 OFDM 系統, 為已廣泛運用於各種商業化無線通訊系統的 OFDM 技術, 提 供更深入與新穎的研究新天地, 未來還有很多研究題目於此, 許多新觀念、新理論與新技 術將被提出, 以符合高速、低複雜度的通訊系統設計。

發表於 HUT-ICCE 2008 的論文, 得到國科會的補助而順利出國參與該盛會。與會中, 直接與各國的專家學者相互討論與請詣, 讓我們的計畫執行獲得相當大的助力, 具體展現 於報告中學理上的新發現, 此外, 我們在發展與驗證理論的過程, 亦開發出整套模擬環境 的系統雛型, 未來有意完成方便與具親和力的介面, 使研究成果能普及且益於產學界之研 發與教學。 


\section{可供推廣之研發成果資料表}

\begin{tabular}{|c|c|}
\hline$\square$ 可申請專利 & 可技術移轉 \\
\hline 國科會補助計畫 & $\begin{array}{l}\text { 計畫名稱：低複雜度區塊碼於高速時-空-頻多輸入-多輸出多路徑衰退 } \\
\text { 通道之設計與分析 } \\
\text { 計畫主持人：嚴雨田教授 } \\
\text { 計畫編號：NSC９6-2221-E-032-003- 學門領域：電信 }\end{array}$ \\
\hline 技術/創作名稱 & $\begin{array}{l}\text { 低複雜度非正交時空區塊碼與快速雷利衰退通道正交分頻多工之設計 } \\
\text { 與分析 }\end{array}$ \\
\hline 發明人/創作人 & 嚴雨田教授 \\
\hline \multirow[b]{2}{*}{ 技術說明 } & $\begin{array}{l}\text { 中文: } \\
\text { 目前被廣泛應用於商業無線通訊系統中的時空區碼都是具正交性質, 然 } \\
\text { 而, 我們提出更一般化的非正交線性區塊碼的設計發展方法, 不只能提 } \\
\text { 供研發工程師更快速的系統驗證平台, 並更能迅速地運用新的編碼設計 } \\
\text { 理論, 產生更適用於無線通訊需求的特殊設計時空區碼。另外, 於時頻 } \\
\text { 訊號領域的正交分頻多工於快速雷利衰退通道之系統設計與分析, 我們 } \\
\text { 指出傳統文獻中對錯誤率分析之不精確的假設條件, 以致與實際有所誤 } \\
\text { 差之處, 並提出數學分析證明之。 }\end{array}$ \\
\hline & $\begin{array}{l}\text { 英文： } \\
\text { The most used transmit diversity employing space-time block code in } \\
\text { practical commercial wireless communication system is confined to the } \\
\text { orthogonal property. However, there are a lot more chances to use } \\
\text { non-orthogonal space-time block to get more advantages over the existing } \\
\text { design. We thus pay the way for the research fellows as well as practical } \\
\text { engineers to develop non-orthogonal codes to best meet the modern } \\
\text { communication need. As for the OFDM systems, we considered the } \\
\text { performance analysis under the fast Ricean fading environments. The } \\
\text { inaccurate mathematical assumption adopted in conventional literature was } \\
\text { pointed out. The discrepancy between the analysis and simulated results } \\
\text { were resolved. }\end{array}$ \\
\hline $\begin{array}{c}\text { 可利用之產業 } \\
\text { 及 } \\
\text { 可開發之産品 }\end{array}$ & 無線通訊 \\
\hline 技術特點 & $\begin{array}{l}\text { 快速的系統驗證平台, 並運用新的設計理論以開發更適於實際環境的無 } \\
\text { 線通訊技術 }\end{array}$ \\
\hline 推廣及運用的價值 & 系統研發與設計驗證平台 \\
\hline
\end{tabular}

$※ 1$. 每項研發成果請填寫一式二份, 一份隨成果報告送繳本會, 一份送貴單位 研發成果推廣單位（如技術移轉中心）。

$※ 2$. 本項研發成果若尚未申請專利, 請勿揭露可申請專利之主要内容。

$※ 3$. 本表若不敷使用, 請自行影印使用。 